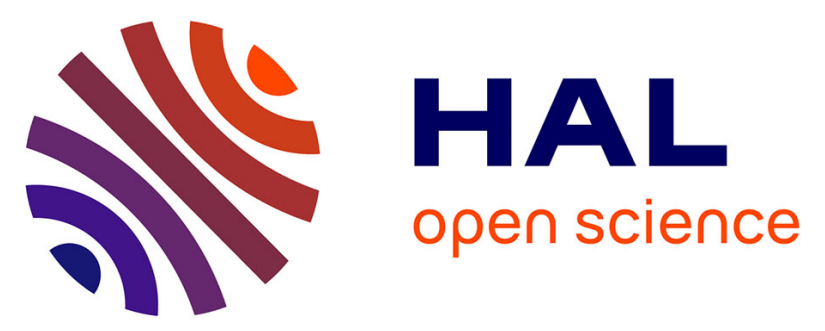

\title{
PdZn or ZnPd: Charge transfer and Pd-Pd bonding as the driving force for the tetragonal distortion of the cubic crystal structure
}

\author{
Matthias Friedrich, Alim Ormeci, Juri Grin, Marc Armbrüster
}

\section{To cite this version:}

Matthias Friedrich, Alim Ormeci, Juri Grin, Marc Armbrüster. PdZn or ZnPd: Charge transfer and $\mathrm{Pd}-\mathrm{Pd}$ bonding as the driving force for the tetragonal distortion of the cubic crystal structure. Journal of Inorganic and General Chemistry / Zeitschrift für anorganische und allgemeine Chemie, 2010, 636 (9-10), pp.1735. 10.1002/zaac.201000097 . hal-00552466

\section{HAL Id: hal-00552466 https://hal.science/hal-00552466}

Submitted on 6 Jan 2011

HAL is a multi-disciplinary open access archive for the deposit and dissemination of scientific research documents, whether they are published or not. The documents may come from teaching and research institutions in France or abroad, or from public or private research centers.
L'archive ouverte pluridisciplinaire HAL, est destinée au dépôt et à la diffusion de documents scientifiques de niveau recherche, publiés ou non, émanant des établissements d'enseignement et de recherche français ou étrangers, des laboratoires publics ou privés. 


\section{PdZn or ZnPd: Charge transfer and Pd-Pd bonding as the driving force for the tetragonal distortion of the cubic crystal structure}

\begin{tabular}{|c|c|}
\hline Journal: & Zeitschrift für Anorganische und Allgemeine Chemie \\
\hline Manuscript ID: & zaac. 201000097.R1 \\
\hline Wiley - Manuscript type: & Article \\
\hline $\begin{array}{r}\text { Date Submitted by the } \\
\text { Author: }\end{array}$ & 06-Apr-2010 \\
\hline Complete List of Authors: & $\begin{array}{l}\text { Friedrich, Matthias; Max-Planck-Institut für Chemische Physik fester } \\
\text { Stoffe } \\
\text { Ormeci, Alim; Max-Planck-Institut für Chemische Physik fester } \\
\text { Stoffe } \\
\text { Grin, Juri; Max-Planck-Institut für Chemische Physik fester Stoffe } \\
\text { Armbrüster, Marc; Max-Planck-Institut für Chemische Physik fester } \\
\text { Stoffe }\end{array}$ \\
\hline Keywords: & ZnPd, PdZn, Chemical bonding, ELI, Homogeneity range \\
\hline
\end{tabular}


PdZn or ZnPd: Charge transfer and Pd-Pd bonding as the driving force for the tetragonal distortion of the cubic crystal structure

\author{
Matthias Friedrich, Alim Ormeci, Yuri Grin, Marc Armbrüster ${ }^{\#}$ \\ \#corresponding author, e-mail: research@armbruester.net, Max-Planck-Institut für \\ Chemische Physik fester Stoffe, Nöthnitzer Str. 40, \\ 01187 Dresden, Germany
}

Dedicated to the $60^{\text {th }}$ birthday of Prof. Dr. Bernd Harbrecht

\begin{abstract}
:
The intermetallic compound $\mathrm{PdZn}$ was reported to possess two modifications, the tetragonal $\mathrm{CuAu}$-type low-temperature phase and the cubic CsCl-type hightemperature phase. The existence of the cubic high-temperature phase at the equiatomic composition could not be proven experimentally. Calculations of the total energy reveal a minimum at $c / a=1.155$, clearly excluding the cubic structure at the equiatomic composition in the system Pd-Zn. Analysis of the chemical bonding applying the electron localizability approach reveals charge transfer from $\mathrm{Zn}$ to $\mathrm{Pd}$ and proves direct Pd-Pd interactions in the (001) plane to be the main reason for the tetragonal distortion of the cubic $\mathrm{CsCl}$-type structural pattern for $\mathrm{ZnPd}$.
\end{abstract}

Keywords: PdZn, ZnPd, chemical bonding, ELI, homogeneity range 


\section{Introduction}

The tetragonal distortion of the $\mathrm{CsCl}$ type of structure towards the $\mathrm{CuAu}$ type of structure has been subject of debate over several decades. Johansson and Linde were the first to explain the tetragonal lattice of $\mathrm{CuAu}$ by ascribing the distortion to the different atomic radii of $\mathrm{Cu}$ and $\mathrm{Au}$ [1]. Schubert showed that the ratio of the atomic radii does not linearly correlate with the ratio of the axes [2]. Hence, the influence of the atomic radii seemed not to be the only driving force for the distortion. The argument, that the tetragonal lattice is formed due to favoured heteroatomic interactions like in tetragonal NiZn [3] - one $\mathrm{Ni}$ atom is surrounded by eight $\mathrm{Zn}$ atoms, but only by four $\mathrm{Ni}$ atoms - was rejected by comparison to $\mathrm{PtCu}$. The latter is not distorted tetragonally, it is slightly rhombohedral; every atom is surrounded by 6 atoms of each kind [2]. Dehlinger suggested another driving force for the distortion [4]. The tetragonal lattice results in new Brillouin zones leading to additional Bragg reflections. Since these allow accommodating electrons in an energetically favourable way, the Fermi energy is decreased by the distortion. Counter arguments for this thesis are supported by the crystal structures of NiZn, PdCd and PtHg which do not show intense additional reflections but still form the $\mathrm{CuAu}$ type of structure. Schubert's model of the Ortskorrelation [2] tried to explain the tetragonal structure by the contribution of a certain number of valence electrons of each atom to stabilization of the crystal structure. Neumann et al. analysed several compounds realizing the $\mathrm{CuAu}$ structure for influence of ionic bonding on the structure. Results showed a correlation between the degree of tetragonality and the enthalpy of formation or degree of ionic bonding, respectively [5]. However, this is contradictory since ionic interactions should favour the more isotropic undistorted CsCl-type. Experimental and quantum chemical investigations of TiAl ( $\mathrm{CuAu}$ type of structure) resulted in the description of covalently bonded $\mathrm{Ti} 4^{4}$ nets in the structure to which the tetragonal distortion was assigned [6,7]. High-pressure experiments on $\mathrm{CuAu}[8]$ revealed that the atomic size ratio plays only a secondary role for the tetragonality in $\mathrm{CuAu}$ type structures. More important are band structure effects, resulting in an energetically favourable way to accommodate the electrons. As already suggested by Schubert [2] and Neumann et al. [5], a single aspect might not solely explain the tetragonal distortion in $\mathrm{CuAu}$ type structures. 
The equiatomic phase in the binary system $\mathrm{Pd}-\mathrm{Zn}$ is usually described with the formula PdZn. The tetragonal structure of the room temperature modification was first reported in 1950 by Nowotny et al. [9]. Later Nowotny et al. [10] and Köster et al. [11] investigated the high temperature region at the composition $\mathrm{Pd}_{2} \mathrm{Zn}$ and $\mathrm{Pd}_{2} \mathrm{Zn}_{3}$ both of which realize the cubic $\mathrm{CsCl}$ structure type. The authors remained unsure, whether the phase ranges of $\mathrm{Pd}_{2} \mathrm{Zn}$ and $\mathrm{Pd}_{2} \mathrm{Zn}_{3}$ merge at high temperatures or if two separate phases exist. To our best knowledge, no experimental evidence of the cubic $\mathrm{CsCl}$-type crystal structure at 50 at.-\% $\mathrm{Pd}$ at elevated temperatures has been reported so far. The latest cumulative phase diagram in [12] is based on earlier work of [13] where the high temperature region is shown as tentative.

Investigating chemical bonding by means of electron localization approach has proven to be an efficient tool in exploring chemical stability and catalytic properties of intermetallic compounds $[14,15]$. For example, the stability of PdGa as a catalyst in the semi-hydrogenation of acetylene to ethylene could be understood by analysing the chemical bonding using the electron localizability indicator [16, 17]. In this context it is worth mentioning, that the intermetallic compound PdZn (better to be described as $\mathrm{ZnPd}$, see the bonding analysis below) plays an important role as catalyst in the steam reforming of methanol $[18,19]$. The formation of the intermetallic compound was detected in situ when applying $\mathrm{Pd} / \mathrm{ZnO}$ as a catalyst, accompanied with a huge increase in selectivity. The density of states of $\mathrm{ZnPd}$ and other compounds realizing the $\mathrm{CuAu}$ or $\mathrm{CsCl}$ type of structures was used to draw conclusions about their catalytic properties in the steam reforming of methanol [20]. In this study, the chemical bonding in the tetragonal and cubic structures of $\mathrm{ZnPd}$ is explored using quantum chemical calculations through the electron localizability indicator (ELI). Furthermore, new experimental data on the binary Pd-Zn phases around 50 at.- $\% \mathrm{Pd}$ are presented.

\section{Experimental}

\section{Synthesis of tetragonal ZnPd}

All procedures are carried out in an argon-filled glove box with $\mathrm{H}_{2} \mathrm{O}$ and $\mathrm{O}_{2}$ concentrations below $0.1 \mathrm{ppm}$. Elemental Zn (99.9999\%, powder, ChemPur) and Pd (99.9\%, powder, Chempur) are weighed with a composition $\mathrm{Zn}_{50} \mathrm{Pd}_{50}$. The mixture is filled in a quartz glass ampoule. After evacuating and sealing the tube, the ampoule is 
placed in a furnace, and the temperature is increased with $5 \mathrm{~K} / \mathrm{h}$ upon the melting point of $\mathrm{Zn}(693 \mathrm{~K})$ and finally raised to $1123 \mathrm{~K}$ with $1 \mathrm{~K} / \mathrm{min}$, where it is held for 6 days. The ampoule is cooled down and the sintered product is ground, sealed into an evacuated quartz glass ampoule again and annealed at $1173 \mathrm{~K}$ for 7 days. After quenching in water, the powder is analysed by X-ray powder diffraction (image plate Guinier camera G670, Huber, $\mathrm{Cu} \mathrm{K}_{\alpha 1}, \lambda=1.54056 \AA$, quartz monochromator, $3^{\circ}<2 \theta<100^{\circ}$; internal standard $\mathrm{LaB}_{6}, a=4.15692 \AA$ ).

\section{Investigation of the homogeneity range of tetragonal $\mathrm{ZnPd}$}

Samples containing 46 at.- $\%$ and 64 at.- $\% \mathrm{Pd}$, respectively, were prepared according to the above synthesis route. The samples were finally annealed at $1173 \mathrm{~K}$ for 5 days. After quenching in water, powders are analysed by X-ray powder diffraction and WDX spectroscopy (CAMECA SX 100, W filament, $25 \mathrm{kV}$ ).

\section{Synthesis of cubic ZnPd}

To obtain the cubic (HT) modification of $\mathrm{ZnPd}$, several quenching attempts were made, all starting from a phase pure powder sample of tetragonal $\mathrm{ZnPd}$. The challenge is melting the compound while minimizing loss of zinc due to evaporation. The first attempt consisted of heating the sample in a thin-walled closed quartz glass ampoule to $1503 \mathrm{~K}$, by referring to [11], followed by annealing for seven hours and finally rapid quenching the ampoule in cold water. Another experiment to obtain the HT modification started with inductive heating of the initial compound inside an open glassy carbon crucible under inert argon atmosphere to $1673 \mathrm{~K}$. After reaching this temperature the crucible is turned upside down and the melt is poured onto a stainless steel plate. Measuring the density of the quenched products by means of a Helium pycnometer (AccuPyc 1330, Micromeritics) was used to obtain information about the composition of the products.

\section{Quantum chemical calculations}

The tight-binding linear-muffin-tin-orbital (TB-LMTO) program [21] in the atomic sphere approximation (ASA) and all-electron full-potential local orbital (FPLO) scheme [22] are used for quantum chemical calculations on tetragonal and cubic $\mathrm{ZnPd}$. The issue of stability regarding the tetragonal and cubic crystal structures is 
addressed by carrying out FPLO total energy calculations within local density (LDA) and generalized gradient (GGA) approximations. For LDA Perdew-Wang [23] and for GGA Perdew-Burke-Ernzerhof [24] parametrizations are used.

The following crystal structure model was used for tetragonal $\mathrm{ZnPd}$ : space group $P 4 / m m m$ (No. 123), Pd in Wyckoff position $1 a$ at $000, \mathrm{Zn}$ in Wyckoff position $1 d$ at 0.50 .50 .5 with cell parameters $a=2.8931(1) \AA$ and $c=3.3426(2) \AA$ as determined experimentally. Calculations on cubic $\mathrm{ZnPd}$ are based on the following structure model: space group $P m \overline{3} m$ (No. 221), $\mathrm{Pd}$ in $1 a$ at $0,0,0, \mathrm{Zn}$ in $1 b$ at $0.5,0.5,0.5$. Since no experimental lattice parameter for cubic $\mathrm{ZnPd}$ is available at 50 at.-\% $\mathrm{Pd}$, $a=3.0513 \AA$ was calculated by linear extrapolation of the cell parameters of cubic $\mathrm{Zn}_{3} \mathrm{Pd}_{2}$ and cubic $\mathrm{ZnPd}_{2}$ [10]. For LMTO-ASA calculations, no interstitial empty spheres were necessary in either structure, because it was possible to reach the total unit cell volumes by atomic spheres with acceptable overlap $(\leq 14 \%)$. The following radii of the atomic spheres are applied for tetragonal $\mathrm{ZnPd}: r(\mathrm{Pd})=1.51 \AA$, $r(\mathrm{Zn})=1.48 \AA$. For cubic $\mathrm{ZnPd}$, the applied radii of the atomic spheres are $r(\mathrm{Pd})=1.52 \AA, r(\mathrm{Zn})=1.49 \AA$. The density of states $(\mathrm{DOS})$ is calculated using a grid of $55^{3} \mathrm{k}$-points for tetragonal $\mathrm{ZnPd}$ and $58^{3} \mathrm{k}$-points for cubic $\mathrm{ZnPd}$, respectively.

Chemical bonding analysis is based on the concept of electron localizability. The electron localizability indicator (ELI, $ク$ ) [25] is evaluated in ELI-D according to [26, 27]. ELI can be calculated by both FPLO [28] and TB-LMTO methods. The topology of ELI is analysed using the program DGrid [29] with integration of the electron density in ELI basins, a procedure similar to that in the quantum theory of atoms in molecules (QTAIM) proposed by Bader [30].

\section{Results and discussion}

\section{Synthesis of tetragonal and cubic $\mathrm{ZnPd}$}

Single phase material of tetragonal $\mathrm{ZnPd}$ was obtained after annealing the pre-reacted powder at $1173 \mathrm{~K}$ as confirmed by X-ray powder diffraction (Fig. 1). The compound is hard and brittle with silvery metallic lustre. Contrary to previously reported synthesis routes which always had to deal with evaporating zinc, this method is capable of preparing the compound with the initial equiatomic $\mathrm{Pd}: \mathrm{Zn}$ ratio. The cell parameters were determined as $a=2.8931(1) \AA$ and $c=3.3426(2) \AA$. The samples for the homogeneity range determination consisted of tetragonal $\mathrm{ZnPd}$ and cubic $\mathrm{ZnPd}_{2}$ 
or cubic $\mathrm{Zn}_{3} \mathrm{Pd}_{2}$, respectively, in accordance to the published phase diagram. Unit cell parameters as well as the composition of $\mathrm{ZnPd}$ in the mixtures are shown in Table 1. The synthesis of cubic $\mathrm{ZnPd}$ in an open glassy carbon crucible, quenched from melt, only yielded zinc poor samples with compositions of $\mathrm{Zn}_{0.66} \mathrm{Pd}_{1.34}$ (according to the density measurements) due to evaporation of zinc. The evaporation of zinc can be avoided if the initial compound is placed inside a quartz glass ampoule which then is quenched from $1503 \mathrm{~K}$. Nevertheless, single phase material of tetragonal ZnPd was obtained instead of cubic $\mathrm{ZnPd}$. Hence, the existence of cubic $\mathrm{ZnPd}$ (50 at.-\% Pd) could not be proven experimentally using the preparation procedures applied.

\section{On the stability of the cubic structure}

Since $c / a=1$ in the tetragonal space group $P 4 / \mathrm{mmm}$ gives the cubic structure, total energy calculations in that space group were performed to compare the energies for different $c / a$ ratios at a given unit cell volume. The results obtained by GGA at the experimental volume of the unit cell are shown in Fig. 2. The lowest total energy is obtained at the experimental $c / a$ value of $\sim 1.155$, while the energy of the cubic structure $(c / a=1)$ is higher by $\sim 10 \mathrm{meV} /$ atom. To determine the volume dependence of the $c / a$ ratio, the $c / a$ ratios of the tetragonal structure are optimized for different unit cell volumes by both LDA and GGA (Fig. 2). In both cases, c/a decreases monotonically with decreasing volume, but even at a volume compression of $\sim 35 \%$, the $c / a$ ratio is around 1.09 , far from the cubic limit of 1 . These results suggest that at larger volumes, which should be attained at elevated temperatures due to thermal expansion, the lowest total energies will be obtained at larger $c / a$ values, which is in clear contradiction to the assumption that the tetragonal structure will transform to the cubic structure at higher temperatures. The theoretical equilibrium volume obtained by GGA (LDA) is $3.8 \%$ larger (4.5\% smaller) than the experimental volume. Both results are within the expected range of deviations for each functional.

As would be expected for both compounds, the major contributions in the DOS originate from the $\mathrm{Zn}-d$ and $\mathrm{Pd}-d$ states (TB-LMTO-ASA results, Fig. 3). The main difference in the density of states is detected around the Fermi energy. In the cubic structure a higher contribution by Pd- $d$ states to the DOS at the Fermi energy is observed, compared to the tetragonal structure. The local peak in the density of states close below the Fermi energy indicates a possible instability of the cubic crystal 
structure in agreement with the total energy calculations. In tetragonal $\mathrm{ZnPd}$, this local peak close to the Fermi energy splits into two smaller peaks at $-1 \mathrm{eV}$ and $+0.5 \mathrm{eV}$, respectively. This change in the electronic structure suggests a Peierls-like distortion stabilising the tetragonal structure in $\mathrm{ZnPd}$.

The topology of calculated electron density for both, the cubic and the tetragonal structure, reveals very similar basins defined by the zero-flux surfaces in the density gradient, the QTAIM atoms (Fig. 4, top). The volume of the QTAIM Pd (16.65 $\left.\AA^{3}\right)$ is smaller than the average value of $22.3 \AA^{3}$ between the atomic volumina of the elemental palladium $\left(29.4 \AA^{3}\right)$ and zinc $\left(15.2 \AA^{3}\right)$. The volume of QTAIM Zn $(11.32$ $\AA^{3}$ ) is even smaller than for metallic zinc. In the chemically similar system Al-Pt [31] this indicated atomic interactions between the components and formation of Pt anions and $\mathrm{Al}$ cations. Indeed, integration of the electron density within the QTAIM reveals charge transfer from $\mathrm{Zn}$ to $\mathrm{Pd}$ for both structures and both calculation methods, in accordance with their electronegativities after Pauling [32]. Following the IUPAC nomenclature, we therefore suggest to describe the compound as $\mathrm{ZnPd}$. Integration of the electron density obtained by the FPLO calculation yields $\mathrm{Zn}^{0.4+} \mathrm{Pd}^{0.4-}$, revealing the important role of the charge transfer in the formation of the cubic and tetragonally distorted body-centred-like structural patterns in the system $\mathrm{Zn}-\mathrm{Pd}$.

The reasons for the tetragonal distortion are visualized by the analysis of the electron localizability indicator for both structural motifs (Fig. 4, middle and bottom). For both structures, the distribution of ELI-D in the inner shells (especially the penultimate third one) around the zinc nuclei is very close to spherical. The basins of the ELI attractors in the valance region are multi-synaptic implying multi-centre $\mathrm{Zn}-\mathrm{Pd}$ bonding interactions (not shown in the figure). In combination with the charge transfer, this suggests polar interaction between $\mathrm{Zn}$ and $\mathrm{Pd}$. Contrary to zinc, in the tetragonal structure the penultimate shell of palladium is significantly structured in the (001) plane compared to weaker structuring in the (100) plane. Such a structuring proved to be a fingerprint for the direct (covalent) interaction between the palladium atoms [33, 34]. This interaction is also reflected by small ELI-D maxima between the $\mathrm{Pd}$ atoms along [100] (Fig. 4, middle). In cubic $\mathrm{ZnPd}$, the structuring is less pronounced as illustrated by the structuring index (the difference between the highest ELI-D value in the examined shell and the ELI-D value at which the localization domain is without a "hole" [35] which is 0.037 for the tetragonal structure and 0.012 for the cubic one). Furthermore, no maxima in ELI-D were calculated between the Pd 
atoms. Thus, the direct Pd-Pd bonding within the $4^{4}$ nets in the (001) plane is the main reason for the tetragonal distortion of the cubic structure in case of $\mathrm{ZnPd}$.

\section{Conclusions}

The existence of the cubic high-temperature phase of equiatomic composition in the binary system $\mathrm{Pd}-\mathrm{Zn}$ could not be proven experimentally and remains uncertain. Tetragonal ZnPd possesses a homogeneity range of 13.8 at.- $\%$ at $1173 \mathrm{~K}$.

Calculations of the total energy reveal a minimum at $c / a=1.155$, clearly excluding the cubic pattern at the equiatomic composition in the system $\mathrm{Zn}-\mathrm{Pd}$. Analysis of the chemical bonding applying the electron localizability approach revealed the charge transfer from $\mathrm{Zn}$ to $\mathrm{Pd}$, justifying the formula $\mathrm{ZnPd}$ instead of PdZn. In addition, direct Pd-Pd interactions in the (001) plane where shown to be the main reason for the tetragonal distortion of cubic $\mathrm{ZnPd}$. 


\section{References}

[1] C.H. Johansson, J.O. Linde, Ann. Phys. 78, 1925, 439.

[2] K. Schubert, Z. Metallkde. 46, 1955, 43.

[3] T. Muto, Sci. Pap. Inst. Phys. Chem. Res. Tokyo 34, 1938, 377.

[4] U. Dehlinger, Z. Phys. 105, 1937, 588.

[5] J.P. Neumann, H. Ipser, Y.A. Chang, J. Less-Comm. Met. 57, 1978, P29.

[6] Z.W. Lu, A. Zunger, A.G. Fox, Acta Metall. Mater. 42, 1994, 3929.

[7] J. Braun, M. Ellner, B. Predel, Z. Metallkde. 86, 1995, 870.

[8] W.K. Wang, H. Iwasaki, J. Phys. Chem. Solids 48, 1987, 559.

[9] H. Nowotny, H. Bittner, Monatshefte für Chemie 81, 1950, 679.

[10] H. Nowotny, E. Bauer, A. Stempfl, Monatshefte für Chemie 82, 1951, 1086.

[11] W. Köster, U. Zwicker, Festschrift 100 Jahre W.C. Heräus, Hanau, 1951, 76.

[12] T.B. Massalski, Binary Alloy Phase Diagrams, $2^{\text {nd }}$ Edition, ASM International, 1990.

[13] M. Hansen, K. Anderko, Constitution of Binary Alloys, $2^{\text {nd }}$ Edition, McGrawHill Book Company, 1958.

[14] M. Armbrüster, W. Schnelle, U. Schwarz, Yu. Grin, Inorg. Chem. 46, 2007, 6319.

[15] K. Kovnir, M. Armbrüster, D. Teschner, T.V. Venkov, F.C. Jentoft, A. KnopGericke, Yu. Grin, R. Schlögl, Sci. Technol. Adv. Mater. 8, 2007, 420.

[16] J. Osswald, R. Giedigkeit, R.E. Jentoft, M. Armbrüster, F. Girgsdies, K. Kovnir, T. Ressler, Yu. Grin, R. Schlögl, J. Catal. 258, 2008, 210.

[17] J. Osswald, K. Kovnir, M. Armbrüster, R. Giedigkeit, R.E. Jentoft, U. Wild, Yu. Grin, R. Schlögl, J. Catal. 258, 2008, 219.

[18] N. Takezawa, N. Iwasa, Cat. Today 36, 1997, 45.

[19] K.M. Neyman, K.H. Lim Z.-X. Chen, L.V. Moskaleva, A. Bayer, A. Reindl, D. Borgmann, R. Denecke, H.-P. Steinrück, N. Rösch, Phys. Chem. Chem. Phys. 9, 2007, 3470 .

[20] A.P. Tsai, S. Kameoka, Y. Ishii, J. Phys. Soc Japan 73, 2004, 3270.

[21] O. Jepsen, A. Burkhardt, O.K. Andersen, The Program TB-LMTO-ASA, Version 4.7, Max-Planck-Institut für Festkörperforschung, Stuttgart, 1999.

[22] K. Koepernik, H. Eschrig, Phys. Rev. B 59, 1999, 1743; for more information: www.fplo.de. 
[23] J.P. Perdew, Y. Wang, Phys. Rev. B 45, 1992, 13244.

[24] J.P. Perdew, K. Burke, M. Ernzerhof, Phys. Rev. Lett. 77, 1996, 3865.

[25] M. Kohout, Int. J. Quantum. Chem. 97, 2004, 651.

[26] M. Kohout, F.R. Wagner, Yu. Grin, Int. J. Quantum Chem. 106, 2006, 1499.

[27] M. Kohout, Faraday Disscuss. 135, 2007, 43.

[28] A. Ormeci, H. Rosner, F.R. Wagner, M. Kohout, Yu. Grin, J. Phys. Chem. A 110, 2006, 1100 .

[29] M. Kohout, DGrid, Version 4.5, Max-Planck-Institut für Chemische Physik fester Stoffe, Dresden, 2010.

[30] R.F.W. Bader, Atoms in Molecules: A Quantum Theory, Oxford University Press, Oxford, 2003.

[31] A. Baranov, M. Kohout, F.R. Wagner, Yu. Grin, W. Bronger, Z. Kristallogr. 222, 2007, 527.

[32] J. Emsley, The Elements, Clarendon Press, Oxford, 1991.

[33] M. Kohout, F.R. Wagner, Yu. Grin, Theor. Chem. Acc. 108, 2002, 150.

[34] F.R. Wagner, V. Bezugly, M. Kohout, Yu. Grin, Chem. Eur. J. 13, 2007, 5724. 
Tables

Table 1: Composition and lattice parameters of the tetragonal $\mathrm{ZnPd}$ phase in the twophase samples

\begin{tabular}{|l|l|l|l|l|}
\hline $\begin{array}{l}\text { Initial composition } \\
\text { / at.-\% }\end{array}$ & $\begin{array}{l}\text { Composition by } \\
\text { WDXS / at.-\% }\end{array}$ & \multicolumn{4}{|l|}{ Lattice parameters / $\AA$} \\
\hline $\mathrm{Zn}_{36} \mathrm{Pd}_{64}$ & $\mathrm{Zn}_{37.1} \mathrm{Pd}_{62.9}$ & $a=2.9532(6)$ & $c=3.269(1)$ & $c / a=1.107$ \\
\hline $\mathrm{Zn}_{54} \mathrm{Pd}_{46}$ & $\mathrm{Zn}_{50.9} \mathrm{Pd}_{49.1}$ & $a=2.8878(2)$ & $c=3.3622(3)$ & $c / a=1.164$ \\
\hline
\end{tabular}




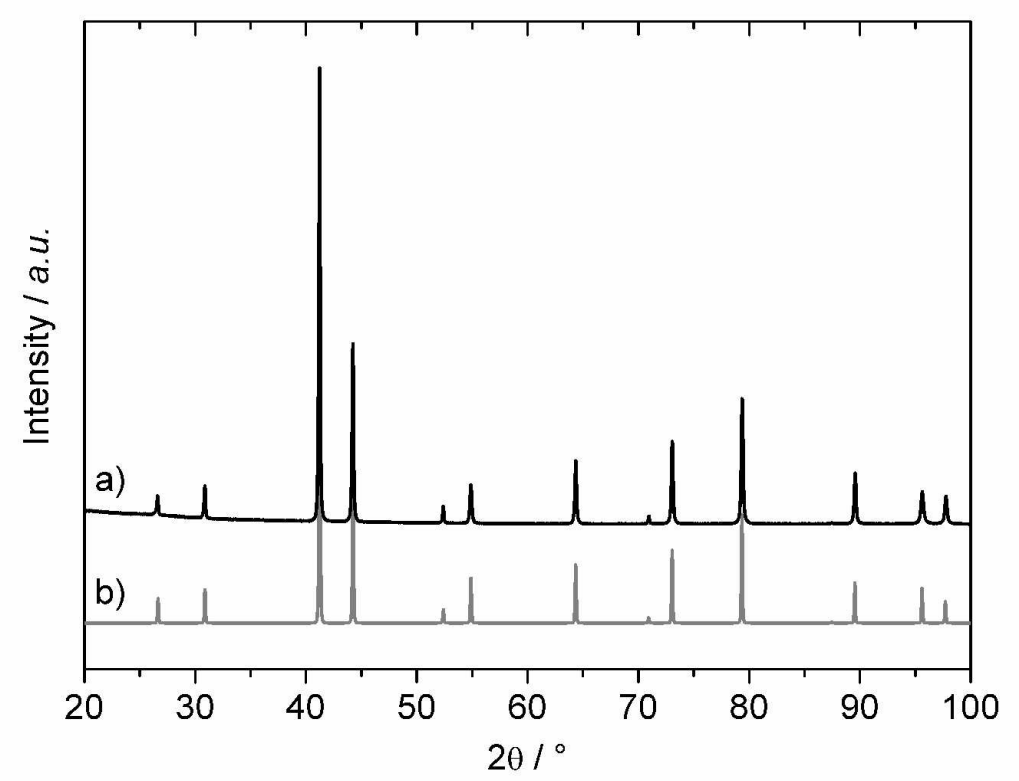

(a) Experimental and (b) calculated X-ray powder diffraction pattern of tetragonal ZnPd. $573 \times 398 \mathrm{~mm}(150 \times 150 \mathrm{DPI})$ 


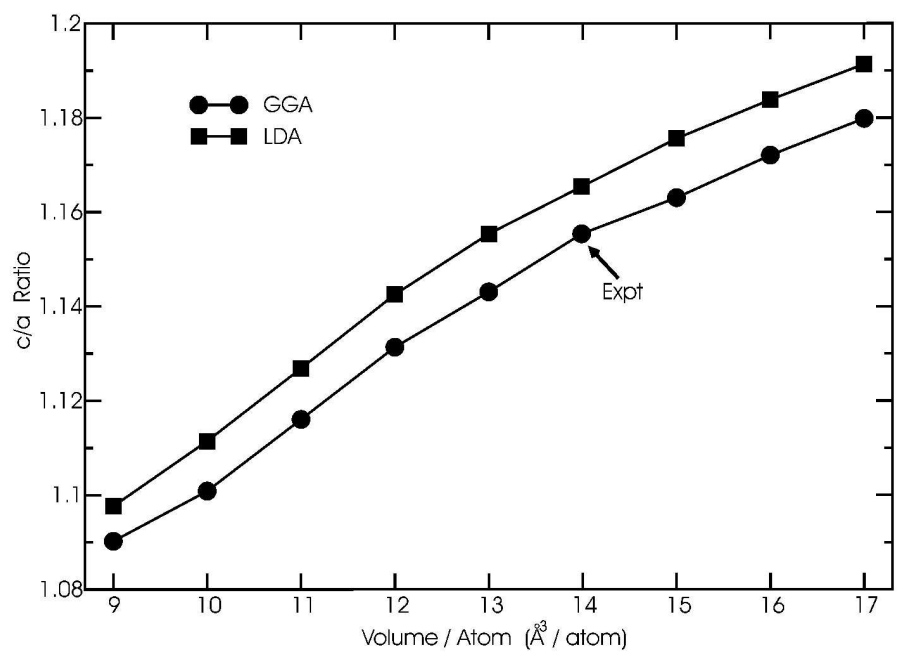

(top) Total energy per atom vs. c/a ratio is obtained within GGA for tetragonal ZnPd at the experimentally observed unit cell volume of $13.989 \AA 3$. The minimum was observed at the experimental $c / a$ value of $\sim 1.155$, the cubic structure with $c / a=1$ has a much higher energy. (bottom) Axial ratio c/a vs. unit cell volume for GGA and LDA calculations (bottom). The arrow marks the experimentally determined $c / a$ ratio and volume. 

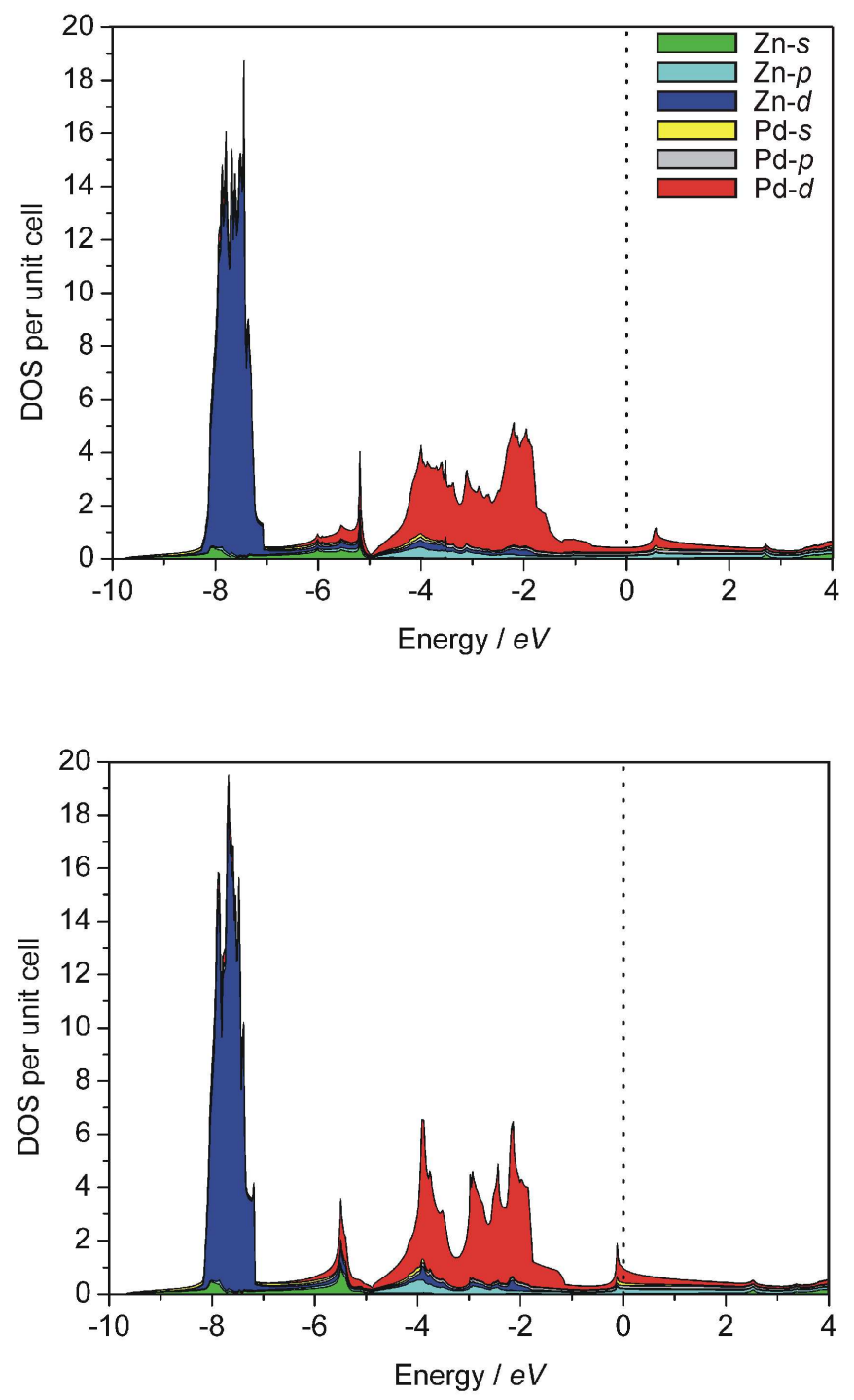

Total and partial electronic DOS for tetragonal ZnPd (CuAu-type, top) and cubic ZnPd (CsCl-type, bottom) as obtained by TB-LMTO-ASA. 
Chemical bonding in ZnPd: (top) QTAIM basins of Pd (blue) and Zn (green) in tetragonal ZnPd (FPLO calculation) with the according electronic populations revealing the charge transfer from $\mathrm{Zn}$ to Pd. (middle) ELI-D distribution in the (100), (010) and (001) planes in tetragonal ZnPd shows strong structuring of the penultimate shell of Pd in the (001) plane as well as small ELI-D maxima between Pd atoms along [100]. (bottom) ELI-D distribution in the (100), (010) and (001) planes in cubic ZnPd shows weaker structuring of the penultimate shell of Pd in all three planes. $155 \times 292 \mathrm{~mm}(600 \times 600$ DPI $)$ 